Article

\title{
Exploiting Olive Mill Byproducts and Other Waste for Organic Weed Management
}

\author{
Ashraf M. Tubeileh ${ }^{1} * \mathbb{0}$, Justin T. Schnorf ${ }^{2}$, Israel Mondragon ${ }^{2}$ and Gary A. Gray ${ }^{2}$ \\ 1 Horticulture and Crop Science Department, California Polytechnic State University, San Luis Obispo, \\ CA 93407, USA \\ 2 Undergraduate student, California Polytechnic State University, San Luis Obispo, CA 93407, USA \\ * Correspondence: atubeile@calpoly.edu; Tel.: +1-805-756-2870
}

Received: 15 June 2019; Accepted: 8 August 2019; Published: 9 August 2019

\begin{abstract}
Weed management represents one of the most serious and costly challenges in organic crop production systems. Agricultural waste/byproducts might present phytotoxicity that can be exploited to control weeds. Two experiments were designed to study the effects of four concentrations of olive vegetation water (OVW) and a control water treatment (with no OVW) on cheeseweed (Malva parviflora L.) seed germination in petri dishes and pots. In a third experiment, two rates of four composts (crop residue mix (CR), olive pomace (OP), dairy/horse manure (DM), and an OP/DM mix) were mixed into a clay-loam soil at 0.10 or $0.20 \mathrm{~L} \mathrm{~L}^{-1}$, to assess their effects on weed number and biomass, in addition to bell pepper (Capsicum annuum L.) growth. In the petri dish experiment, the three highest OVW concentrations completely prohibited germination during the five-week duration of the study. For the pot experiment, $25 \mathrm{~mL}$ application of OVW significantly delayed and reduced cheeseweed germination, with the reduction being proportional to the concentration of OVW. In the third experiment, composts reduced weed dry matter (composed mostly of purslane (Portulaca oleracea $\mathrm{L}$.)), with the CR compost being the most effective, reducing total weed biomass by $67 \%$ compared to the control. CR10 and DM10 tended to increase bell pepper yields, although none of the plant parameters was significantly affected by the compost treatments.
\end{abstract}

Keywords: olive vegetation water; olive mill wastewater; olive pomace; manure compost; weeds; organic agriculture; germination; Malva parviflora L.; Portulaca oleracea $\mathrm{L}$.

\section{Introduction}

Organic weed management has always suffered from a lack of tools. In addition, the existing tools are expensive and have limited effectiveness. Moreover, the ever-expanding weed resistance to herbicides has been adding to the challenges of weed control for conventional growers. A particular weed of interest is cheeseweed (Malva parviflora L.), which is becoming a problem in Mediterranean climates due to its tolerance to many herbicides [1]. In addition, it is capable of germinating at a wide range of temperatures $\left(5-37^{\circ} \mathrm{C}\right)$ and presents different dormancy attributes [2], making its control even harder. In the meantime, in olive- (Olea europaea L.) producing areas, olive oil processing activities result in large amounts of wastewater (aka olive vegetation water, OVW) and olive pomace $(\mathrm{OP})$, which have polluting properties resulting from their content of organic compounds [3]. OVW contains high concentrations of lignins and tannins, which give it a characteristic dark color. In addition, this material is toxic to micro-organisms and plants due to its load of phenolic compounds, long-chain fatty acids, low $\mathrm{pH}$, and salts $[4,5]$. This phytotoxicity has often been an issue restricting the feasibility of soil application of OVW to take advantage of its nutrient content for crop growth [6]. For example, a soil surface application of OVW in an olive orchard suppressed stomatal conductance and decreased soil mineral nitrogen, but increased soil micronutrients [7]. A $150 \mathrm{~m}^{3} \mathrm{ha}^{-1}$ soil application 
of OVW suppressed photosynthetic parameters, including the net carbon assimilation rate, in olive trees [8]. Plant germination seems to be one of the factors most sensitive to OVW. Germination of chickpeas (Cicer arietinum L.), durum wheat (Triticum durum Desf.), maize (Zea mays L.), and tomatoes (Solanum lycopersicum L.) was significantly reduced by OVW applications [9]. In tomatoes, OVW application rates of $80 \mathrm{~m}^{3} \mathrm{ha}^{-1}$ immediately decreased the relative germination rate to $20 \%$, but this rate recovered to about $60 \%$ three days after the application [10]. Vegetable crops appear to be the most negatively affected by OVW soil application [11]. A lab bioassay indicated gradual germination inhibition of lettuce (Lactuca sativa L.) with increasing OVW rates resulting in $7.67 \%, 0.13 \%$, and $0 \%$ germination rates at 80,160 , and $500 \mathrm{~m}^{3} \mathrm{ha}^{-1}$, respectively, compared to the untreated control germination rate of $87.6 \%$ [4]. This phytotoxicity might present an opportunity for weed management in organic and herbicide-resistance situations. Application of OVW suppressed the germination of certain weeds like redroot pigweed (Amaranthus retroflexus L.) by up to $90 \%$, but was not so effective against other weeds [12]. Likewise, compared to the untreated control, the application of OVW at $10 \mathrm{~L} \mathrm{~m}^{-2}$ reduced weed cover by 59\%, 69\%, 36\%, 71\%, and 76\% for annual bluegrass (Poa annua, L.) shepherd's purse (Capsella bursa-pastoris (L.) Medik.), chickweed (Stellaria media (L.) Vill.), chamomile (Matricaria chamomilla L.), and henbit dead-nettle (Lamium amplexicaule L.), respectively [13]. A smaller dose of $5 \mathrm{~L} \mathrm{~m}^{-2}$ was less effective at reducing weed pressure, and did not affect chickweed at all. OP at 3 and $10 \mathrm{~L} \mathrm{~m}^{-2}$ was even more effective than the liquid waste treatments at reducing the weed cover of all those species [13]. Other studies have shown mixed results of sun-dried OP on weed germination, with some weeds like purslane and redroot pigweed being controlled, while others like puncturevine (Tribulus terrestris L.), purple nutsedge (Cyperus rotundus L.), and Johnsongrass (Sorghum halepense (L.) Pers.) were not affected by the treatment [14]. These studies show the potential of using olive mill byproducts and other agricultural waste composts in weed control, especially in organic crop production, where tools are limited and expensive. Still, our knowledge of the effects of this waste on weed pressure is very limited in terms of the weed species affected and doses needed. The objectives of this study were:

- to evaluate the effect of OVW application on cheeseweed germination, and

- $\quad$ to assess the weed suppression ability of different composts with or without OP.

\section{Materials and Methods}

This work consisted of three experiments conducted at the California Polytechnic State University, San Luis Obispo, CA, using OVW or composts. The OVW and OP were sourced from La Panza Ranch in Templeton, CA, which has a three-phase olive press. The OVW was kept in the refrigerator at $2{ }^{\circ} \mathrm{C}$ until use. The grape pomace consisted of seeds and skins of red-wine grapes, and was sourced from Cagliero Ranch in Paso Robles, CA. The composting process is described in Section 2.3.

\subsection{Experiment 1: OVW Effects on Cheeseweed Germination in Petri Dishes}

The effect of four dilutions of OVW and a control water treatment (with no OVW) on cheeseweed seed germination was studied in petri dishes (Figure 1). The experiment was laid out according to a completely randomized design with six replicates. Experimental units comprised 10 cheeseweed seeds that were disinfected in a 1\% sodium hypochlorite solution and placed on towel paper in petri dishes. Each petri dish received $25 \mathrm{~mL}$ (corresponding to $3.13 \mathrm{~L} \mathrm{~m}^{-2}$ ) from one of the OVW dilutions presented in Table 1. $\mathrm{pH}$ values and electrical conductivity of the final treatments are also presented in Table 1. 




Figure 1. Picture showing petri dishes after treatment applications. From left to right, top row presents treatments $1-3$ and bottom row presents treatments 4 and 5 .

Table 1. Composition, $\mathrm{pH}$, and electrical conductivity of treatments used in Experiment 1.

\begin{tabular}{cccc}
\hline Treatment & Description & PH & Electrical Conductivity $\left(\mathbf{m S ~} \mathbf{c m}^{\mathbf{- 1}}\right)$ \\
\hline T1 & No OVW + 100\% tap water (Control) & 7.4 & 0.66 \\
T2 & 25\% OVW + 75\% tap water & 5.1 & 3.39 \\
T3 & $50 \%$ OVW + 50\% tap water & 5.0 & 5.48 \\
T4 & 75\% OVW + 25\% tap water & 4.9 & 6.65 \\
T5 & 100\% OVW (as is from press, no dilution) & 4.9 & 7.23 \\
\hline
\end{tabular}

All petri dishes were then incubated in a growth chamber at $25{ }^{\circ} \mathrm{C}$ day/ $18{ }^{\circ} \mathrm{C}$ night with a photoperiod of $16 \mathrm{~h}$. Water was added thereafter in small amounts to keep the paper and seeds moist. Germination was observed daily, with a final germination count after five weeks of application. Any seed that had germinated a primary root of $2 \mathrm{~mm}$ or more was considered germinated.

\subsection{Experiment 2: Effect of OVW on Cheeseweed Emergence in Soil-Filled Pots}

In this experiment, PVC pots (10 $\mathrm{cm}$ top diameter and $12 \mathrm{~cm}$ deep) were filled with a clay-loam soil collected from the topsoil $(0-15 \mathrm{~cm})$ at the Cal Poly Organic Farm $\left(35^{\circ} 18^{\prime} 15^{\prime \prime} \mathrm{N}, 120^{\circ} 40^{\prime} 21^{\prime \prime} \mathrm{W}\right)$ on 2 August 2018. The soil analysis is shown in Table 2. The soil had a natural, very high cheeseweed seed bank $\left(>2500\right.$ weed $\mathrm{m}^{-2}$ ) from past weed pressure. The pots were placed in a greenhouse with natural lighting. The indoor maximum temperatures ranged between $30^{\circ} \mathrm{C}$ and $35^{\circ} \mathrm{C}$ and minimum temperatures between $18{ }^{\circ} \mathrm{C}$ and $22{ }^{\circ} \mathrm{C}$. The pots were watered to $75 \%$ field capacity, then one application of $25 \mathrm{~mL}$ of treatments 1-5 mentioned in Experiment 1 was applied to each pot. This application rate corresponds to $3.13 \mathrm{~L} \mathrm{~m}^{-2}$. To keep the soil moist, tap water was applied as needed to maintain the soil around $75 \%$ field capacity. The experiment was laid out according to a completely randomized design with five replicates. The number of cheeseweed seeds emerged in pots was recorded periodically, twice a week for two weeks.

Table 2. Chemical properties of the soil used in Experiments 2 and 3.

\begin{tabular}{ccccccccccccc}
\hline Soil PH & Organic Matter & $\mathbf{N O}_{3}-\mathbf{N}$ & Olsen $\mathbf{P}$ & $\mathbf{K}$ & $\mathbf{M g}$ & $\mathbf{C a}$ & $\mathbf{S}$ & $\mathbf{Z n}$ & $\mathbf{M n}$ & $\mathbf{C u}$ & $\mathbf{F e}$ & $\mathbf{B}$ \\
\hline & $\left(\mathbf{g ~ k g}^{-1}\right)$ & & \multicolumn{8}{c}{$\left(\mathbf{m g ~ k g}^{-\mathbf{1}}\right)$} \\
\hline 7.43 & 38 & 5.48 & 15.3 & 270 & 806 & 2576 & 23.9 & 2.33 & 16.2 & 6.30 & 60.7 & 0.85 \\
\hline
\end{tabular}

\subsection{Experiment 3: Effect of Composts on Weed Pressure in Bell Peppers}

Two rates of four composts (crop residue mix (CR), olive pomace (OP), dairy/horse manure (DM), and $\mathrm{OP} / \mathrm{DM}$ mix) were assessed to determine the effects on weed pressure. The $\mathrm{CR}$ was sourced from Engle and Gray (Santa Maria, CA, USA). It comprised a combination of vegetables, strawberry crowns, 
and grape pomace. The manure compost consisted of dairy and horse manures mixed with wood chips with a starting $\mathrm{C} / \mathrm{N}$ ratio around 25 . Composts were prepared aerobically in windrows during the winter and spring of 2018 at the Cal Poly composting unit according to the California Department of Food and Agriculture and organic certification guidelines. The composting process lasted for six months and composts were mechanically turned a minimum of five times. The composts were deemed mature when temperature stabilized and ammonia levels dropped below $4 \mathrm{mg} \mathrm{g}^{-1}$ using a Solvita ${ }^{\circledR}$ (Solvita, Mt Vernon, ME, USA) compost kit. The OP/DM mix contained an equal proportion of OP and DM. A full analysis of these composts is given in Table 3. Each of those composts was applied at 0.10 or $0.20 \mathrm{~L} \mathrm{~L}^{-1}$ soil and thoroughly mixed with a clay loam soil (see Table 2 for soil properties before mixing) before filling in 10-L pots, to imitate mixing in the topsoil in the field. This arrangement resulted in nine treatments (Table 4 ).

Table 3. Chemical analysis of the composts used in Experiment 3.

\begin{tabular}{ccccc}
\hline Nutrient/Salt/Characteristic & CR & OP & DM & OP/DM \\
\hline Total $\mathrm{N}\left(\mathrm{g} \mathrm{kg}^{-1}\right)$ & 14 & 14 & 14 & 17 \\
Ammonia $\left(\mathrm{mg} \mathrm{kg}^{-1}\right)$ & 17 & $<10$ & 13 & 21 \\
Nitrate nitrogen $\left(\mathrm{mg} \mathrm{kg}^{-1}\right)$ & 240 & 1.2 & 430 & 15 \\
Organic $\mathrm{N}\left(\mathrm{g} \mathrm{kg}^{-1}\right)$ & 14 & 14 & 14 & 17 \\
Phosphorus $\left(\mathrm{P}_{2} \mathrm{O}_{5}\right)\left(\mathrm{g} \mathrm{kg}^{-1}\right)$ & 8.9 & 1.2 & 13 & 9.1 \\
Total phosphorus $\left(\mathrm{g} \mathrm{kg}^{-1}\right)$ & 3.90 & 0.55 & 5.70 & 4.00 \\
Potassium $\left(\mathrm{K}_{2} \mathrm{O}\right)\left(\mathrm{g} \mathrm{kg}^{-1}\right)$ & 13 & 5.40 & 17 & 14 \\
Total potassium $\left(\mathrm{g} \mathrm{kg}^{-1}\right)$ & 11 & 4.50 & 14 & 12 \\
Calcium $\left(\mathrm{g} \mathrm{kg}^{-1}\right)$ & 24 & 4.00 & 25 & 18 \\
Magnesium $\left(\mathrm{g} \mathrm{kg}^{-1}\right)$ & 6.00 & 0.50 & 16.0 & 11.0 \\
Sulfate $\left(\mathrm{mg} \mathrm{kg}^{-1}\right)$ & 2500 & 34 & 1200 & 530 \\
Copper $\left(\mathrm{mg} \mathrm{kg}^{-1}\right)$ & 71 & 9.90 & 53 & 130 \\
Zinc $\left(\mathrm{mg} \mathrm{kg}^{-1}\right)$ & 190 & 12 & 210 & 11,000 \\
Iron $\left(\mathrm{mg} \mathrm{kg}^{-1}\right)$ & 11,000 & 1200 & 18,000 & 300 \\
Manganese $\left(\mathrm{mg} \mathrm{kg}^{-1}\right)$ & 300 & 18 & 500 & 27 \\
Boron $\left(\mathrm{mg} \mathrm{kg}^{-1}\right)$ & 22 & 14 & 21 & 1900 \\
Sodium $\left(\mathrm{mg} \mathrm{kg}^{-1}\right)$ & 1600 & 97 & 3300 & 2200 \\
Chloride $\left(\mathrm{mg} \mathrm{kg}^{-1}\right)$ & 3700 & 190 & 2800 & 8.71 \\
pH value & 8.1 & 5.47 & 8.4 & 2.60
\end{tabular}

Table 4. Compost and rate treatment combinations used in Experiment 3.

\begin{tabular}{cc}
\hline Treatment Mix & Treatment Name \\
\hline Control with no compost & Control \\
Crop residue mix 0.10 L L & CR10 \\
Crop residue mix 0.20 L L-1 & CR20 \\
OP 0.10 L L & OP10 \\
OP 0.20 L L & OP20 \\
Dairy manure 0.10 L L-1 & DM10 \\
Dairy manure 0.20 L L-1 & DM20 \\
OP and manure 0.10 L L & OP/DM10 \\
OP and manure $0.20 \mathrm{~L} \mathrm{~L}^{-1}$ & OP/DM20 \\
\hline
\end{tabular}


Per the University of California Cooperative Extension recommendations, the equivalent of $200 \mathrm{~kg} \mathrm{~N} \mathrm{ha}^{-1}$ was added at soil mixing, using a chicken residue fertilizer (8:5:1 NPK) as a source. One day after soil mixing, bell pepper (Capsicum annuum L.) cv. 'Huntington' plugs were transplanted into the pots on 2 August 2018 and the pots were grown outside to imitate field growing conditions. Pots were laid out according to a completely randomized design with six replicates. The plants were watered 1-2 times a day to avoid any water stress. Data were collected during the third and fourth weeks after transplanting. The parameters monitored included plant height, number of leaves, fruit production and relative leaf chlorophyll concentration using SPAD-502 Plus (Konica Minolta, Tokyo, Japan). All these parameters were measured twice, on 13 and 23 August 2018. Fruits were harvested once they reached $6 \mathrm{~cm}$ or more in diameter. Only plants producing fruits exceeding this threshold were considered in the analysis. The last harvest was performed on 19 October 2018. SPAD absorbance readings were taken on the youngest mature leaf. For weeds, weed numbers were counted per species in each pot. Weeds were cut at the soil surface at four weeks after planting, chopped into $4-5 \mathrm{~cm}$ pieces and placed in an oven at $75^{\circ} \mathrm{C}$ until constant weight was achieved to determine biomass production for each species.

\subsection{Statistical Analyses}

Weed seed germination data were log transformed before being subjected to statistical analysis. All data were analyzed according to a single-factor ANOVA using the IBM SPSS Statistics version 26.0 software package (IBM Corp., Armonk, NY, USA) [15]. When factor effects were significant, mean separation was performed using Tukey's honestly significant difference (HSD) test and differences were considered significant at the $P<0.05$ level.

\section{Results}

\subsection{Effect of OVW on Cheeseweed Germination in Petri Dishes}

All OVW water treatments significantly $(P<0.0001)$ decreased cheeseweed germination in petri dishes (Figure 2). Treatments T3, T4, and T5 completely inhibited germination throughout the duration of the study, while treatment $\mathrm{T} 2(25 \%$ OVW) resulted in $3.33 \%$ germination rate at the end of the incubation period, compared to $16.7 \%$ in the T1 treatment (control with $0 \%$ OVW). Furthermore, the first seed germinated in the T2 treatment took nine days longer to germinated than the control (T1) treatment (data not shown), indicating an inhibitory or delaying effect of OVW on cheeseweed seed germination.



Figure 2. Cheeseweed germination in petri dishes that received $25 \mathrm{~mL}$ of OVW at five different strengths using dilutions with tap water (T1: 0\% OVW, T2: 25\% OVW, T3: 50\% OVW, T4: 75\% OVW, T5: 100\% OVW). Error bars represent \pm standard error. Bars sharing the same letter are not statistically different according to Tukey's HSD test (at $P<0.05$ ). 


\subsection{Effect of OVW on Weed Emergence in Soil-Filled Pots}

The application of $25 \mathrm{~mL}$ OVW to soil with heavy cheeseweed seed bank decreased the cheeseweed emergence rate right after application (Figure 3). The suppression of cheeseweed emergence was proportional to the concentration of OVW. The differences between the control T1 treatment and all OVW treatments became significant on day 2 after application and remained so until day 7 after application, except on day 4 (Table 5). The suppression was proportional to the concentration of OVW, with this trend becoming clear after day 7 . T5 had less than half the emergence rate observed in the $\mathrm{T} 1$ treatment throughout the study. Between days 5 and 6, T1 was not statistically different from T3, mainly due to the high variability. Between days 6 and 8, cheeseweed germination accelerated in all OVW treatments annulling the previous significant differences with the control treatment, except between $\mathrm{T} 1$ and $\mathrm{T} 5$. By day 8 , all differences between treatments were not significant, and this trend remained until the end of the experiment. However, it is interesting to note that some of the weeds that germinated in treatments T2 and T3 had died after day 11.

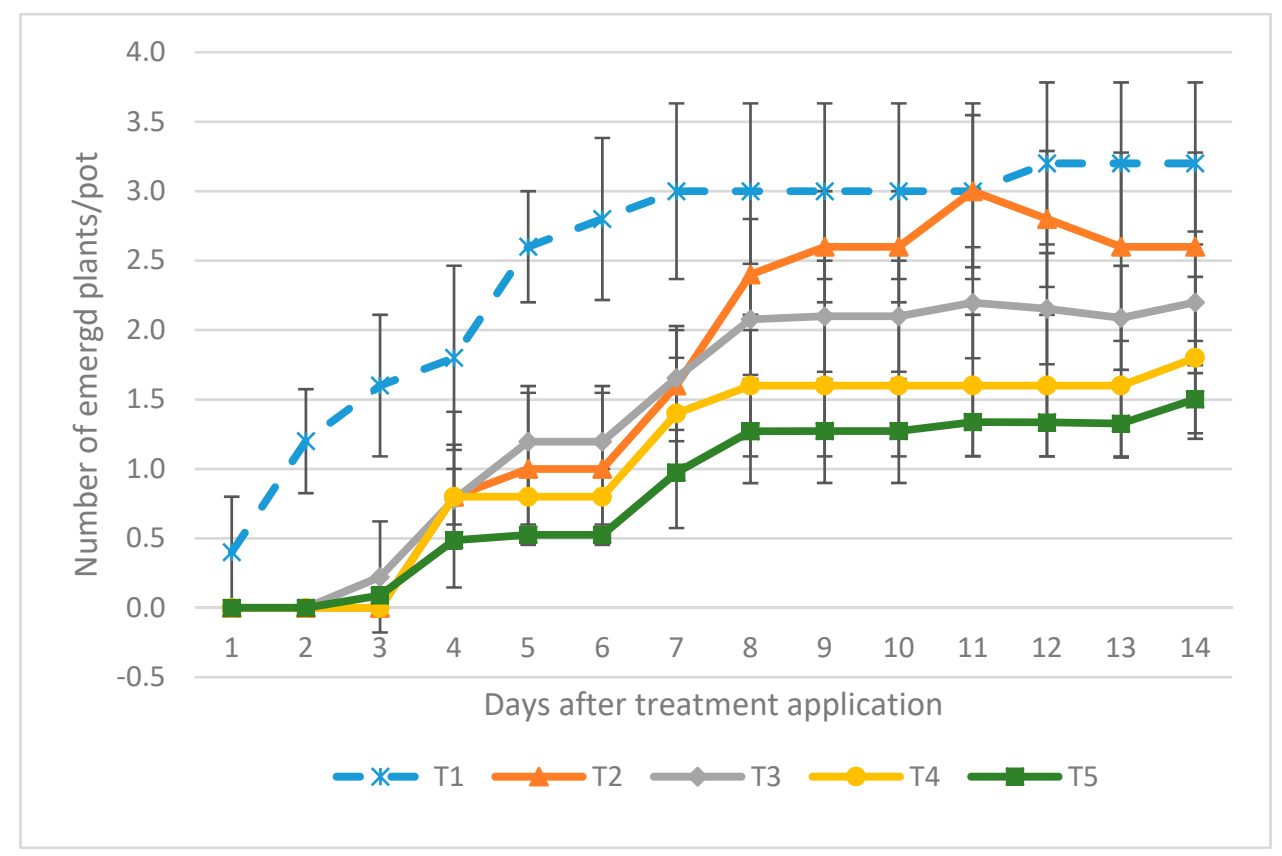

Figure 3. Number of cheeseweed plants emerging in pots that received $25 \mathrm{~mL}$ of OVW at five different strengths diluted with tap water (T1: 0\% OVW, T2: 25\% OVW, T3: 50\% OVW, T4: 75\% OVW, T5: 100\% OVW). Error bars represent \pm standard error.

Table 5. $P$ values for effect of $25 \mathrm{~mL}$ olive vegetation water application on cheeseweed emergence in soil-filled pots.

\begin{tabular}{ccccccccccccccc}
\hline DAA $^{\mathbf{1}}$ & $\mathbf{1}$ & $\mathbf{2}$ & $\mathbf{3}$ & $\mathbf{4}$ & $\mathbf{5}$ & $\mathbf{6}$ & $\mathbf{7}$ & $\mathbf{8}$ & $\mathbf{9}$ & $\mathbf{1 0}$ & $\mathbf{1 1}$ & $\mathbf{1 2}$ & $\mathbf{1 3}$ & $\mathbf{1 4}$ \\
\hline $\mathrm{P}$ & 0.431 & 0.000 & 0.003 & 0.13 & 0.000 & 0.002 & 0.016 & 0.096 & 0.08 & 0.08 & 0.082 & 0.054 & 0.113 & 0.267 \\
\hline \multicolumn{1}{c}{ DAA: Days after application. }
\end{tabular}

\subsection{Compost Pot Experiment}

\subsubsection{Weather information}

The San Luis Obispo area enjoys Mediterranean weather with warm dry summers and mild wet winters. The weather parameters recorded during the experimental period are presented in Figure 4. 


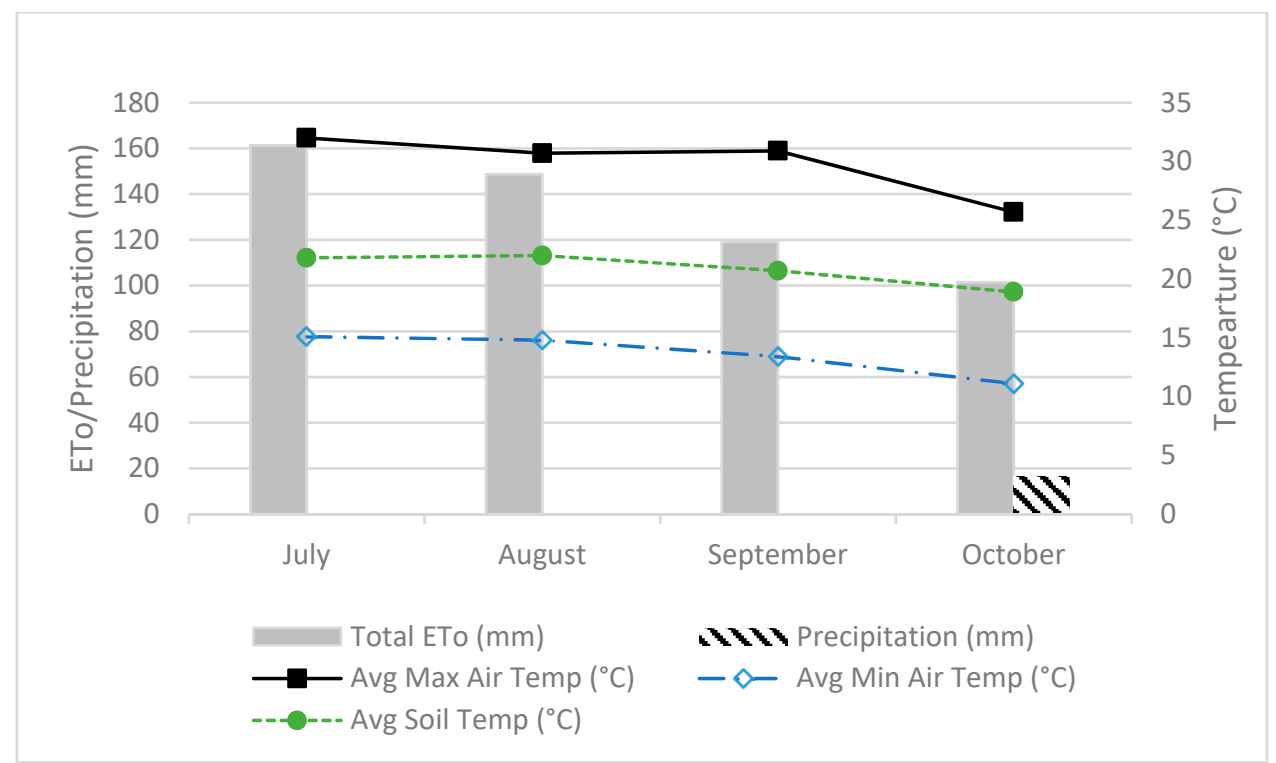

Figure 4. Weather data recorded during experimental period using a CIMIS station on site. ETo: Reference evapotranspiration.

\subsubsection{Weed numbers}

Composts did not have any significant effect $(P=0.23)$ on the total number of weeds per pot (Figure 5). The main weed observed was purslane, with lower numbers of redroot pigweed, lambs quarters (Chenopodium album L.), cheeseweed, and some grasses (mostly wall barley (Hordeum murinum L.)). Similar to total weeds, compost treatments did not significantly affect $(P=0.293)$ purslane numbers, although a suppressive trend was observed with all treatments, especially OP/DM10 (Figure 6). The control treatment had a total of 14 purslane weeds per pot, compared with 5.5-12.6 weeds per pot for the compost treatments.

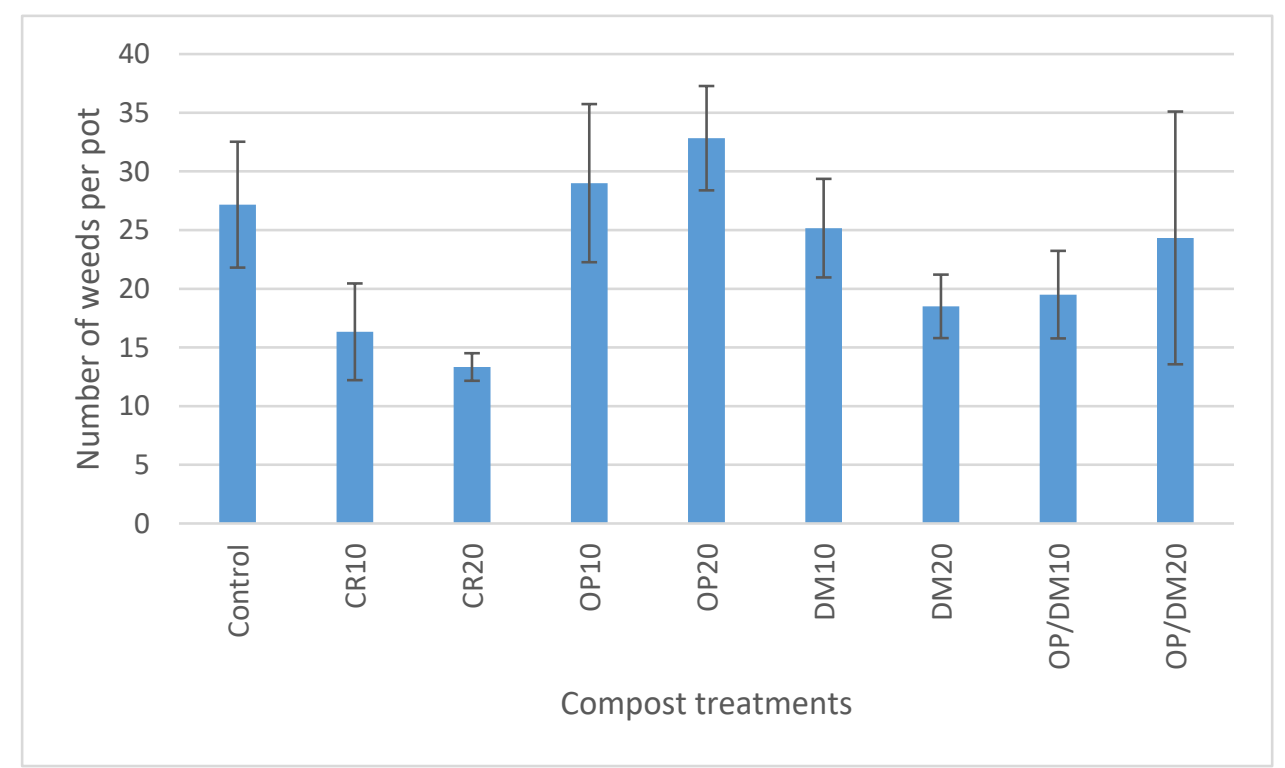

Figure 5. Number of weeds per pot as affected by different compost sources and rates. Error bars represent \pm standard error $(P=0.23, n=6)$. 


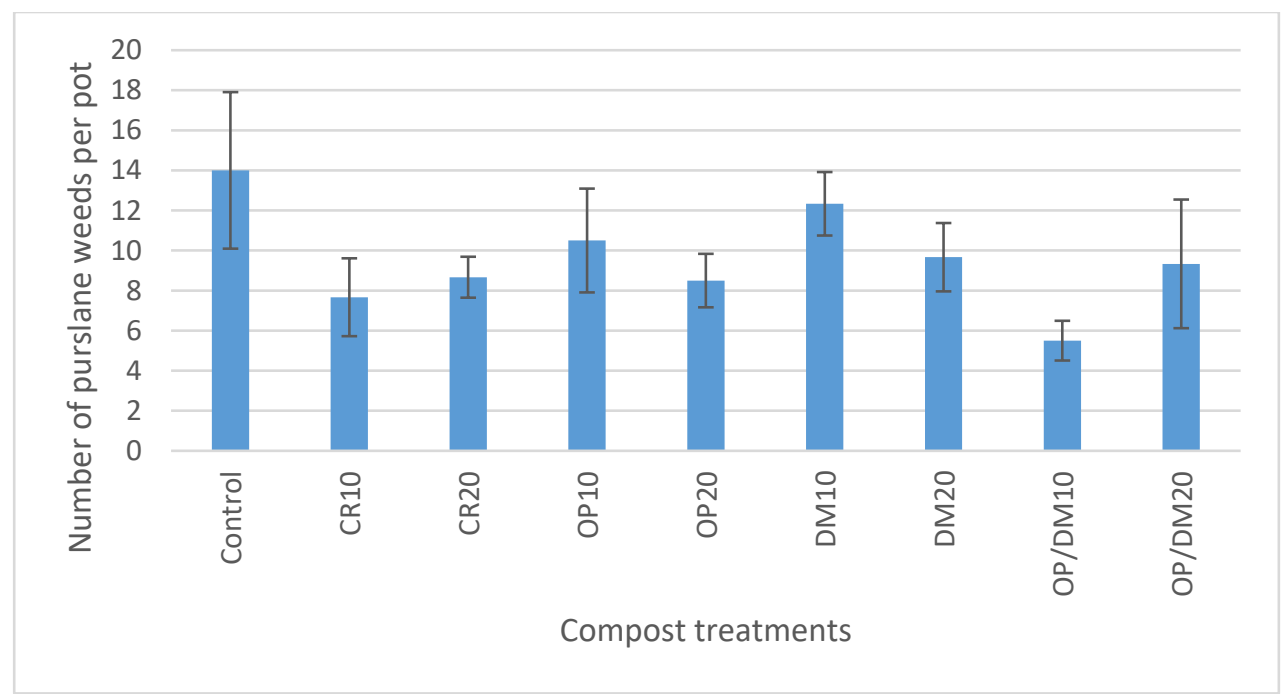

Figure 6. Number of purslane weeds per pot as affected by different compost sources and rates. Error bars represent \pm standard error $(P=0.293, n=6)$.

\subsubsection{Weed dry matter production}

More importantly than the number of weeds, total weed dry matter production was significantly $(P=0.021)$ reduced by several compost treatments (Figure 7$)$. The best suppression was observed with the CR10 treatment, in which weed biomass was suppressed by $67 \%$ compared to the control. Given that purslane was the major weed observed, it was analyzed separately. Compost showed a significant $(P=0.006)$ suppressive effect on purslane dry matter production (Figure 8$)$. The purslane dry matter production values in the compost treatments were $23.4 \%$ (OP20) to $48.5 \%$ (DM20) the values obtained in the control treatment.



Figure 7. Total weed dry matter production as affected by different compost sources and rates. Error bars represent \pm standard error $(P=0.021, n=6)$. Bars sharing the same letter are not statistically different according to Tukey's HSD test (at $P<0.05$ ). 




Figure 8. Purslane dry matter production per pot as affected by different compost sources and rates. Error bars represent \pm standard error $(P=0.006, n=6)$. Bars sharing the same letter are not statistically different according to Tukey's HSD test (at $P<0.05$ ).

\subsubsection{Bell pepper plant health and production}

Composts did not have any significant effect on plant height or the number of leaves at the two dates of measurements (Table 6, Figure 9). Similarly, SPAD absorbance on both dates of measurements was not affected by the compost treatments. However, it is noteworthy to highlight that SPAD absorbance on 23 August tended to drop at the higher compost rate compared to the lower rate, especially for CR and DM (Figure 10). For these two materials, the SPAD absorbance at the higher dose was lower than the lower dose by $17 \%$ and $22 \%$, respectively.

Table 6. $P$ values for effect of two application rates of four composts on plant growth and health parameters.

\begin{tabular}{cc}
\hline Parameter & $\boldsymbol{P}$-Value \\
\hline SPAD Absorbance 13 August & 0.213 \\
SPAD Absorbance 23 August & 0.159 \\
Plant height 13 August & 0.405 \\
Plant height 23 August & 0.393 \\
Number of leaves 13 August & 0.127 \\
Number of leaves 23 August & 0.08 \\
Cumulative fruit production & 0.025 \\
\hline
\end{tabular}

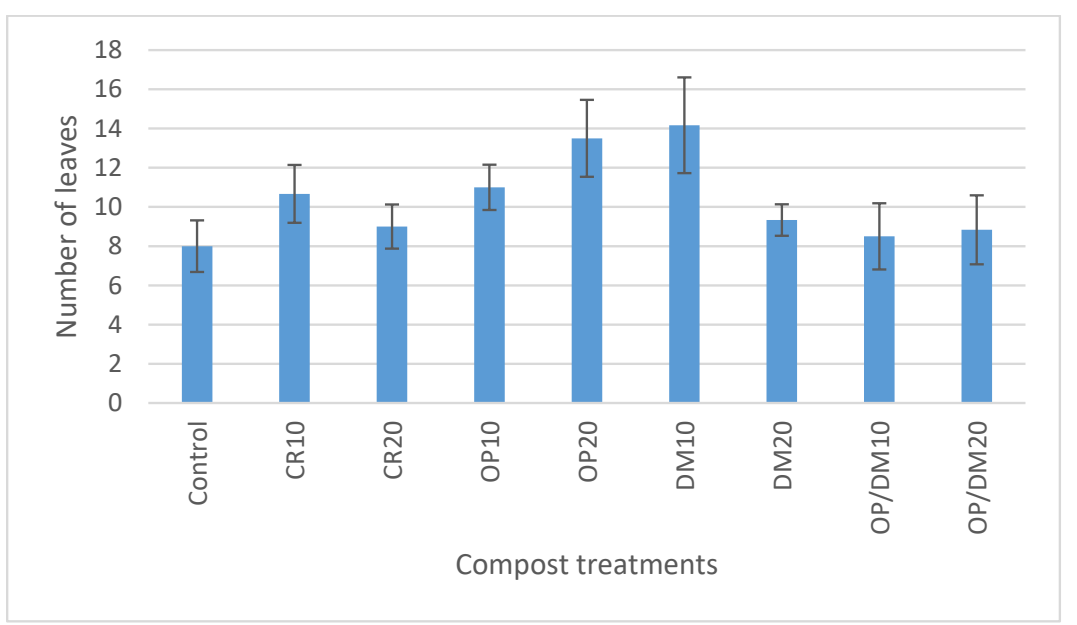

Figure 9. Number of leaves of bell pepper plants as affected by different compost sources and rates. Error bars represent \pm standard error $(P=0.08, n=6)$. 


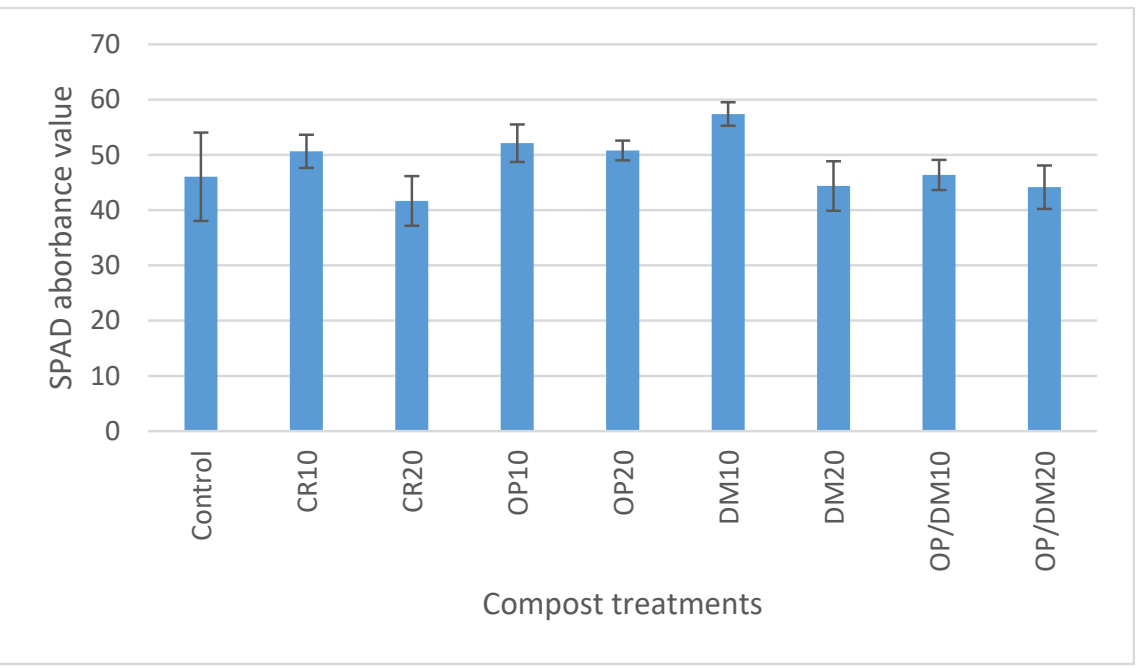

Figure 10. SPAD absorbance on 23 August 2018 as affected by different compost sources and rates. Error bars represent \pm standard error $(P=0.159, n=6)$.

Fruit production was significantly affected by compost application (Table 6). However, Tukey's HSD test failed to detect any differences between means. Nevertheless, treatments CR10 and DM10 presented almost double the yields of the non-amended control treatment (Figure 11).

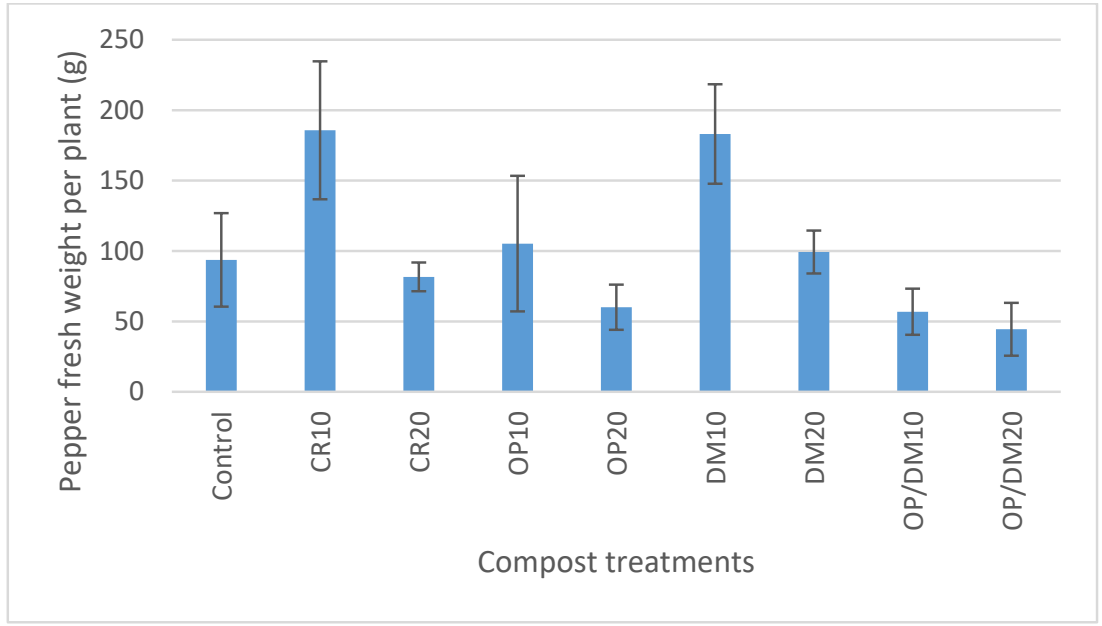

Figure 11. Fresh weight production of bell pepper fruits per plant as affected by different compost sources and rates. Error bars represent \pm standard error $(P=0.025, n=6)$.

\section{Discussion}

OVW generally presented inhibitory or suppressive effects on weed seed germination, especially at full strength or higher concentrations ( $\mathrm{T} 5$ and T4, respectively). OVW contains phytotoxic polyphenols such as catechol, 4-methylcatechol, tyrosol, hydroxytyrosol, and oleuropein [16] in addition to many amino acids [17] and flavonoids [5]. These materials present specific toxicity to crops. For example, in a study involving tomatoes and vegetable marrow (Cucurbita pepo L.) hydroxytyrosol was harmful only to tomatoes, while catechol and tyrosol were harmful only to vegetable marrow [16]. Fatty acids present in OVW such as cinnamic acid [17] result in xylem poles with a greater number of cells and a greater emission of lateral roots, leading to lower plant growth [18]. The combination of cinnamic acid and flavonoids leads to the premature formation of fibers by the phloem [18]. Other modes of action might be involved, as some short-chain fatty acids (e.g., capric and caprylic acids) act as desiccants against some weed species [19]. 
It is important to note that the maximum germination rate observed in the control treatment in the petri dish experiment was only 17\%, indicating a high level of innate dormancy in cheeseweed seeds. This confirmed previous findings showing a 5\% germination rate in fresh seeds increasing to $47 \%$ after a storage period of 13 months [20]. This dormancy presents a problem to weed control efforts and might need to be overcome for effective control to be achieved.

The phytotoxic effect of OVW observed on weeds in our study was more obvious in the petri dishes (Experiment 1) compared to the pot experiment (Experiment 2), as the latter delayed germination rather than inhibiting it. This is in agreement with observations from a similar petri dish experiment showing a complete inhibition of tomato and chicory (Cichorium intybus L.) seed germination when treated with full strength OVW [21]. The lower inhibitory effect in the soil compared to petri dishes can be attributed to the diluting effect of the soil and the irrigation water added afterwards to keep the soil moist in the pots. Furthermore, water application, albeit small, might have pushed OVW below the rootzone. Mekki et al. [22] have shown that polyphenols can leach down to $1.20 \mathrm{~m}$ in the soil. In addition, the soil and microbial processes might have accelerated the degradation of phenolic compounds in OVW. The phytotoxicity in our experiments lasted for a week or so before starting to fade away. A study in Tunisia showed that 20\% concentrated OVW prohibited Brassica cernua (Thunb.) Matsum. (synonym of Brassica juncea (L.) Czern.) germination during a three-day assay, but with further diluted treatments achieved the same germination rate as the untreated control only three days after application [22]. Piotrowska et al. [10] noticed a 20\% reduction in tomato germination at $40 \mathrm{~m}^{3}$ OVW ha ${ }^{-1}$ compared to $>80 \%$ reduction at $80 \mathrm{~m}^{3} \mathrm{ha}^{-1}$. On top of the dilution and rate level effects, OVW phytotoxicity in our study appeared to have decreased with time allowing more weed seeds to germinate. This confirmed findings by Piotrowska et al. [10], who showed a germination recovery after three days of application. The vanishing of the OVW effects on weed seed germination indicated that the rate used in our experiments could be increased to achieve higher and more permanent inhibitory effects.

Composts reduced weed growth, in terms of number and biomass. The $\mathrm{C}_{4}$ plant purslane was the main weed present in the pots and was considerably controlled by composts, resulting in less than half the dry matter in the untreated control. This finding on purslane confirms previous results showing that sun-dried OP gradually reduced purslane numbers from 339 plants $\mathrm{m}^{-2}$ in untreated control to 34.3, 24.8, and 11 plants $\mathrm{m}^{-2}$ in 20, 30, and $40 \mathrm{t} \mathrm{OP} \mathrm{ha}^{-1}$ applications, respectively [14]. Although some studies showed no phytotoxic effect of composted OP, the presence of phytotoxicity in mature composted OP depends on the composting time [23] and the particle size of the pomace, with particles over $1 \mathrm{~mm}$ retaining some phytotoxicity and presenting a germination index around 50\% [24]. Similarly, cress (Lepidium satioum L.) germination index was correlated to the length of the composting process of OP [23].

CR and DM composts sharply increased bell pepper fruit yields when applied at lower rates $(10 \%)$, most likely due to the lower weed competition, as discussed above. This yield increase was not observed at higher compost application rates, as the composts might have resulted in immobilization of soil mineral nitrogen, therefore limiting plant nutrition and cancelling out any potential benefits from reduced weed competition. It is well established that low-nitrogen composts might result in the immobilization of soil inorganic nitrogen for weeks or months. Paul and Beauchamp [25] have shown that soil inorganic nitrogen significantly dropped after addition of composted beef cattle manure and remained so until the end of their experiment after 12 weeks of incubation. Another observation that supports this hypothesis is the lower SPAD absorbance (Figure 10) we observed at higher compost rates, which might have resulted from lower soil mineral nitrogen. As for the OP and OP/DM treatments, the OP might have presented some residual phytotoxicity that did not allow bell pepper plants to fully benefit from the reduced weed competition, although no symptoms were detected in the plants. Several authors have shown that the composting process decreases the OP polyphenol content by one-half (composting for three months [26]) to two-thirds (composting for 22 weeks [23]), leaving 
the final polyphenol concentration below $10 \mathrm{mg} \mathrm{g}^{-1}$. Total phenols in OP decreased by $93 \%$ after 12 months of composting [27].

The stronger negative effect of OP composts on weed germination compared to bell pepper transplant growth might imply a stronger effect of this material on seeds than on seedling roots. A possible mode of action might involve stimulating soil microorganism feeding/degradation of weed seeds. Another explanation for the lack of effect on plants could be the selectivity of OP phytotoxicity. Boz et al. [14] have shown suppressive effects on certain weeds (e.g., purslane), but no effect on crops (okra (Abelmoschus esculentus (L.) Moench), fava bean (Vicia faba L.), onions (Allium сера L.)) or several other weeds (common lambs quarters, puncturevine, purple nutsedge, wild radish (Raphanus raphanistrum L.), and Johnsongrass). On some other weeds like yellow sweetclover (Melilotus officinalis (L.) Lam.), the effect was not consistent from year to year. The same authors showed only a partial control of black nightshade (Solanum nigrum L.), which is in the same family as peppers, indicating that peppers might be tolerant to this material. The selective phytotoxicity of hydroxytyrosol, catechol, and tyrosol [16] was discussed earlier in this section.

\section{Conclusions}

OVW represents a promising option for cheeseweed control, especially when applied before the crop is planted. This tool could be very useful in no-till situations or where mechanical cultivation is not an option. The direct application of OVW to cheeseweed seeds was more effective at reducing and delaying germination compared to soil application, although these phytotoxic effects decreased with time. Higher application rates or multiple applications will be needed to increase the effectiveness of this material at reducing weed seed germination and growth in soil. All composts at different rates reduced weed numbers and dry matter production compared to the untreated control. Composts did not negatively reduce bell pepper plant growth compared to the non-amended control, indicating that the benefits from compost applications will at least balance out any phytotoxic effects. The composts investigated in this study can be used to control purslane. More research is needed to determine the effects of these materials on other weeds. More application rates of OVW also need to be studied.

Author Contributions: Project conceptualization, funding acquisition, project administration, methodology, and writing were performed by A.M.T. Experiments were conducted by J.T.S., I.M., and G.A.G.

Funding: This research was funded by the California State University Agricultural Research Institute, grant numbers 58878 and 58974, and Cal Poly CAFES Summer Undergraduate Research Program.

Acknowledgments: In-kind donations of olive vegetation water compost feedstocks by La Panza Ranch and Cal Poly Compost Unit are appreciated. Thanks are due to Kevin Piper and Mike Bridgman for their organization and help with the composting process. The constructive comments from three anonymous reviewers have greatly improved this manuscript and are greatly appreciated.

Conflicts of Interest: The authors declare no conflict of interest. The funders had no role in the design of the study; in the collection, analyses, or interpretation of data; in the writing of the manuscript, or in the decision to publish the results.

\section{References}

1. Wu, J.Y.; Dastgheib, F. Effects of Various Herbicides and Surfactants on Mallow (Malva spp.). In Proceedings of the 18th Asian-Pacific Weed Science Society Conference, Beijing, China, 28 May-2 June 2001; Asian-Pacific Weed Science Society: Beijing, China, 2001; pp. 589-593.

2. Michael, P.J.; Steadman, K.J.; Plummer, J.A. Climatic regulation of seed dormancy and emergence of diverse Malva parviflora populations from a Mediterranean-type environment. Seed Sci. Res. 2006, 16, 273-281. [CrossRef]

3. Fiorentino, A.; Gentili, A.; Isidori, M.; Monaco, P.; Nardelli, A.; Parrella, A.; Temussi, F. Environmental effects caused by olive mill wastewaters: Toxicity comparison of low-molecular-weight phenol components. J. Agric. Food. Chem. 2003, 51, 1005-1009. [CrossRef]

4. Pierantozzi, P.; Zampini, C.; Torres, M.; Isla, M.I.; Verdenelli, R.A.; Meriles, J.M.; Maestri, D. Physico-chemical and toxicological assessment of liquid wastes from olive processing-related industries. J. Sci. Food Agric. 2012, 92, 216-223. [CrossRef] [PubMed] 
5. El-Abbassi, A.; Saadaoui, N.; Kiai, H.; Raiti, J.; Hafidi, A. Potential applications of olive mill wastewater as biopesticide for crops protection. Sci. Total Environ. 2017, 576, 10-21. [CrossRef]

6. Mekki, A.; Dhouib, A.; Sayadi, S. Review: Effects of olive mill wastewater application on soil properties and plants growth. Int. J. Recycl. Org. Waste Agric. 2013, 2, 15. [CrossRef]

7. Tubeileh, A.; Abdeen, M. Effect of one-time olive-mill waste water application on yield and water relations of olive trees. Acta Hortic. 2017, 303-306. [CrossRef]

8. Mechri, B.; Cheheb, H.; Boussadia, O.; Attia, F.; Ben Mariem, F.; Braham, M.; Hammami, M. Effects of agronomic application of olive mill wastewater in a field of olive trees on carbohydrate profiles, chlorophyll a fluorescence and mineral nutrient content. Environ. Exp. Bot. 2011, 71, 184-191. [CrossRef]

9. El Hadrami, A.; Belaqziz, M.; El Hassni, M.; Hanifi, S.; Abbad, A.; Capasso, R.; Gianfreda, L.; El Hadrami, I. Physico-chemical characterization and effects of olive oil mill wastewaters fertirrigation on the growth of some mediterranean crops. J. Agron. 2004, 3, 247-254.

10. Piotrowska, A.; Iamarino, G.; Rao, M.A.; Gianfreda, L. Short-term effects of olive mill waste water (OMW) on chemical and biochemical properties of a semiarid Mediterranean soil. Soil Biol. Biochem. 2006, 38, 600-610. [CrossRef]

11. Barbera, A.C.; Maucieri, C.; Cavallaro, V.; Ioppolo, A.; Spagna, G. Effects of spreading olive mill wastewater on soil properties and crops, a review. Agric. Water. Manag. 2013, 119, 43-53. [CrossRef]

12. Cayuela, M.L.; Millner, P.D.; Meyer, S.L.F.; Roig, A. Potential of olive mill waste and compost as biobased pesticides against weeds, fungi, and nematodes. Sci. Total Environ. 2008, 399, 11-18. [CrossRef] [PubMed]

13. Boz, O.; Dogan, M.N.; Albay, F. Olive processing wastes for weed control. Weed. Res. 2003, 43, 439-443. [CrossRef]

14. Boz, O.; Ogüt, D.; Kır, K.; Doğan, M.N. Olive processing waste as a method of weed control for okra, faba bean, and onion. Weed Technol. 2009, 23, 569-573. [CrossRef]

15. IBM SPSS Statistics. Version 26; IBM Corp.: Armonk, NY, USA, 2019.

16. Capasso, R.; Cristinzio, G.; Evidente, A.; Scognamiglio, F. Isolation, spectroscopy and selective phytotoxic effects of polyphenols from vegetable waste waters. Phytochemical. 1992, 31, 4125-4128. [CrossRef]

17. Bianco, A.; Buiarelli, F.; Cartoni, G.; Coccioli, F.; Jasionowska, R.; Margherita, P. Analysis by liquid chromatography-tandem mass spectrometry of biophenolic compounds in olives and vegetation waters, Part I. J. Sep. Sci. 2003, 26, 409-416. [CrossRef]

18. Ribeiro, R.C.; Feitoza, R.B.B.; Lima, H.R.P.; De Carvalho, M.G. Phytotoxic effects of phenolic compounds on Calopogonium mucunoides (Fabaceae) roots. Aust. J. Bot. 2016, 63, 679-686. [CrossRef]

19. Coleman, R.; Penner, D. Desiccant activity of short chain fatty acids. Weed Technol. 2006, 20, 410-415. [CrossRef]

20. Chauhan, B.S.; Gill, G.; Preston, C. Factors affecting seed germination of little mallow (Malva parviflora) in southern Australia. Weed Sci. 2006, 54, 1045-1050. [CrossRef]

21. Komilis, D.P.; Karatzas, E.; Halvadakis, C.P. The effect of olive mill wastewater on seed germination after various pretreatment techniques. J. Environ. Manag. 2005, 74, 339-348. [CrossRef]

22. Mekki, A.; Dhouib, A.; Sayadi, S. Polyphenols dynamics and phytotoxicity in a soil amended by olive mill wastewaters. J. Environ. Manag. 2007, 84, 134-140. [CrossRef]

23. Alburquerque, J.A.; Gonzálvez, J.; García, D.; Cegarra, J. Measuring detoxification and maturity in compost made from "alperujo", the solid by-product of extracting olive oil by the two-phase centrifugation system. Chemosphere 2006, 64, 470-477. [CrossRef] [PubMed]

24. Gómez-Muñoz, B.; Hatch, D.J.; Bol, R.; García-Ruiz, R. The Compost of Olive Mill Pomace: From a Waste to a Resource-Environmental Benefits of Its Application in Olive Oil Groves. In Sustainable Development-Authoritative and Leading Edge Content for Environmental Management; InTech Publishing: Seoul, South Korea, 2012; ISBN 978-953-51-0682-1.

25. Paul, J.W.; Beauchamp, E.G. Short-term nitrogen dynamics in soil amended with fresh and composted cattle manures. Can. J. Soil Sci. 1994, 74, 147-155. [CrossRef]

26. Hachicha, S.; Sallemi, F.; Medhioub, K.; Hachicha, R.; Ammar, E. Quality assessment of composts prepared with olive mill wastewater and agricultural wastes. Waste Manag. 2008, 28, 2593-2603. [CrossRef] [PubMed]

27. Ait Baddi, G.; Hafidi, M.; Merlina, G.; Revel, J.C. Characterization and identification of polyphenols during composting of olive mill waste. Agrochimical 2003, 47, 161-172.

(C) 2019 by the authors. Licensee MDPI, Basel, Switzerland. This article is an open access article distributed under the terms and conditions of the Creative Commons Attribution (CC BY) license (http://creativecommons.org/licenses/by/4.0/). 